The Politics of Sound and Image: Eisenstein, Artifice and Acoustic Montage in Contemporary Feminist Cinema

Debbie Ging

[in Jean Antoine-Dunne with Paula Quigley (eds.) The Montage Principle: Eisenstein in New Cultural and critical Contexts. Amsterdam, New York: Rodopi, 2004, pp. 6795]

This essay analyses the (potential) relevance of Eisenstein's cinema and, in particular, his thoughts on cinematic sound, to contemporary feminist filmmaking. Both E. Ann Kaplan and Fredric Jameson have argued that deconstruction/fragmentation is no longer an effective political strategy in contemporary art practice, particularly in the United States, where fragmentation has become a part of everyday life (Jameson, 1981: 54). This is probably true of postmodern culture in general, whose fragmentation of images, it could be argued, has less to do with political impact than with an insatiable need for new visual stimuli. The films discussed in this essay point toward a possible 'middle-ground', which insists neither on alienating the viewer nor on eliminating the dialectic. This concept of a non-alienating counter-cinema is closely associated with Eisenstein's goal of combining narrative/emotional engagement and political agitation without recourse to realist/naturalist devices. The purpose of this essay is to demonstrate the ways in which acoustic montage might facilitate such a 'middle-ground' in contemporary feminist cinema.

Much of the contemporary debate surrounding Eisenstein focuses on the relevance of montage in today's culture and, in particular, on the extent to which this revolutionary art form has been co-opted by mainstream culture and thus divested of its original power. Visual montage has become the aesthetic mainstay of everything from MTV pop videos to flyers selling life insurance policies. Rather than rejecting antihegemonic belief systems, the argument goes, global capitalism has simply pirated them and, in doing so, has diffused any threat that they might pose to dominant ideologies. It is necessary to say that, although MTV-style editing owes much to the legacy of Soviet montage, this superficial and almost wholly stylistic use of the technique is limited, at very best, to metric and rhythmic montage. As David Bordwell has pointed out: 'An advertisement featuring a roller-skating pizza-delivery boy is not comparable to the Odessa Steps sequence merely because both use 'fast cutting.' Indeed Eisenstein's whole theory insists that techniques may function differently 
according to context' (Bordwell, 1993: 266). It is also useful to distinguish between what Hal Foster refers to as a postmodernism of reaction, which best describes the MTV aesthetic, and a postmodernism of resistance, whereby the use of parody, irony and re-appropriation continue to challenge the status quo (Foster, 1985: xii).

Although Eisenstein's films and Soviet photo-montage are not generally directly associated with a revolutionary feminist politics, they still offer powerful techniques to feminist filmmakers in the context of a postmodernism of resistance. Just as Esfir Schub edited documentary footage together to achieve effects of irony, pathos and absurdity, many (for the most part little-known) contemporary filmmakers have employed visual and acoustic montage to present their own subjective visions of history, visions hitherto presented to us as 'objective' by realist cinema. In this essay I argue that bourgeois realism, the staple format of mainstream narrative fiction, is problematic for feminist filmmaking. Meanwhile, although the concepts of alienation and deconstruction, as embodied, for example, in Brechtian theatre, have played a vital role in much feminist work of the 1960s and 1970s (Yvonne Rainer, Barbara Hammer, Jan Oxenburg), to merely continue an aesthetic of pure deconstruction and fragmentation is also problematic: firstly, because in a postmodern culture, the process of fragmentation in art no longer has any real political impact and secondly, because it positions women negatively in culture (Kaplan: 1988: 140) rendering them 'other', alternative and thereby necessarily marginalised.

The question of whether feminist cinema can move beyond a politics of deconstruction without resorting to the illusionist realism of mainstream film is not new, in the sense that it echoes many of the wider debates concerning mainstream and avant-garde cinema. However, this essay explores the notion that a positive or constructionist feminist cinema could be informed by some of the key concepts of Eisensteinian montage and, more specifically, by strategies of acoustic montage. Central to this concept of feminist film is the refusal to deny audience pleasure, coupled with an acknowledgement of the artifice inherent in all representations of reality. I examine a number of contemporary films with a view to demonstrating how radical use of sound can enable politics and pleasure to meet dialectically, opening up potential routes toward a non-alienating counter-cinema or a cinema that, according to Laura Mulvey, could evoke a sense of 'passionate detachment' in the viewer (Mulvey, 1975: 18). 


\section{The Problem with Realism}

Eisenstein's work is frequently addressed in terms of two distinct phases, the early 'montage of attractions' and the later, more sophisticated "fused structure of contrapuntal currents" or synaesthesia (Eisenstein, 1987: 386-396), wherein diverse components were interwoven to form a more systematic unity. The earlier work, being closer to the Russian formalist principle of "making strange" or alienating the viewer into a state of raised consciousness (Strike, October, The Battleship Potemkin), is generally deemed to be more radical, while that later films, with their focus on unity and the emotional power of cinema, are often criticized for their political limitations and affinity with conventional narrative. According to Peter Wollen, Eisenstein - unlike Brecht - failed to develop an artistic language of rational political argument because of his obsession with the emotional impact of cinema (Wollen, 1972: 69). However, I challenge the notion that rational argument and emotional response are mutually exclusive, and contend that it is precisely from this dialogical tension that Eisenstein's films, as well as the contemporary works discussed here, derive their power.

Although it has been argued - and much audience research has shown that - classical Hollywood cinema also offers dialectical possibilities, there remain significant distinctions between Eisenstein's attempts to harness the emotive power of cinema and Hollywood's use of realism to do the same. Eisenstein maintained that artistic syntax was dependent on two instinctive human principles: that of hunting (plot as pursuit) and that of basket weaving (interweaving) (Eisenstein, 1987: 265). ${ }^{1}$ Although his films did not lack plot, Eisenstein was primarily concerned with the second of these principles, namely the multi-layered fabrication of meaning from diverse if not opposite elements and the response that the combination of these elements could or should evoke in the viewer. His aim was to stimulate the viewer emotionally but also to engage thought. Thus, while the narratives undeniably involve the viewer in a story, the juxtaposition of images is unashamedly contrived and anti-naturalist. As a result, the audience is encouraged to consider concepts at metaphorical/symbolic (and sometimes allegorical) levels, rather than being asked to identify with a representational reality. By contrast, the editing devices used in classical Hollywood

\footnotetext{
${ }^{1}$ It is worth noting that in early societies hunting was predominantly the task of men, while basketweaving was performed mostly by women. A pattern of linear narrative logic is still observed in male action movies today, while feminist cinema focuses more on thematic complexities and cyclical narrative forms (also associated with oral storytelling traditions).
} 
cinema - and indeed in most mainstream cinema generally - are designed to suture the viewer into an illusion of reality, whereby the metaphorical and the symbolic are submerged beneath the realist narrative, arguably leaving the ideology to work at a much more subconscious level.

It is also worth distinguishing between the socio-political contexts in which Soviet and Hollywood cinema developed, in terms of how audiences understood and engaged with the medium. Unlike the majority of western cinema-goers, audiences in Soviet Russia of the 1930s would have been aware of the films' political/propagandist significance, albeit to varying degrees. Hollywood cinema, on the other hand, is primarily conceived of as entertainment and, with the exception of scholarly criticism, is rarely viewed in an overtly political context. Those films that do purport to deal with topical issues such as rape, AIDS or political spin-doctoring (e.g. The Accused, Philadelphia, Wag the Dog) are so dependent on dramatic closure that they tend to restore the audience's faith in legal and other social institutions rather than encouraging critique of them. Indeed, due to their perceived "realism" and emotional/political/ideological resolution to the crisis at hand, it is arguable that audiences leave the cinematic space in the (subconscious) belief that there is nothing more to be done. By contrast, Eisenstein's techniques of plastic composition open up considerable possibilities for building tension, exposing contradictions and arousing political/subjective consciousness.

Significantly, many avant-garde feminist, gay and lesbian filmmakers of the 1970s argued that realism was an inadequate medium for their political goals and that objectivity was neither possible nor desirable. In other words, it was not enough to use the camera simply to show or reveal a particular 'reality', or what Eisenstein referred to as representation from without or reality that is 'illusory' (Eisenstein, 1987: 332). Instead, the filmmaker must represent from within by creating a 'reality' which is broken down into signs and symbols and which achieves meaning through the collision of these signs. The idea of 'reality' was especially problematic for feminists since, as Eileen McGarry has noted, before the filmmaker even arrives on the scene, reality is already coded "first in the infrastructure of the social formation (human economic practice) and secondly by the superstructure of politics and ideology" (McGarry, 1975: 50). Thus far, the predominant way in which feminist filmmakers have sought to tackle this problem is through the persistent interrogation and 
subversion of the cinematic apparatus itself. ${ }^{2}$ Meanwhile, many critics have concluded that realism, in spite of its claims to truth and the supposed good intentions of its directors, is largely inappropriate for the purposes of radical political filmmaking (Mulvey, 1979; Johnston, 1985).

In spite of this - or perhaps because of it - contemporary feminist filmmakers who have previously worked in a distinctly avant-garde tradition (Patricia Rozema, Jane Campion, Pat Murphy, Rose Troche, Sally Potter) have been moving consistently toward cinematic realism, while montage is steadily becoming the staple diet of pop video producers and advertisers. Films that are variously classed as 'feminist' such as Chasing Amy, The Piano, The Colour Purple, Girl's Town or Nora, although they deal thematically with important feminist issues, do not challenge the (patriarchal) grammar of the cinematic apparatus itself. This is not to say that these films are insignificant as feminist texts. On the contrary, qualitative audience research shows that they have been received positively by large female audiences and have had an important impact on both men and women's understanding of gender relations. However, although a film such as Girl's Town carries a profoundly political message, its discursive range and impact are significantly neutralised by its realist aesthetic. As such it draws the audience into the narrative and engages them emotionally in the theme of sexual abuse, while failing to tackle the actual structures which accommodate the oppression of women. By comparison, Marleen Gorris' A Question of Silence interrogates patriarchal logic not only within the narrative but also through its subversive use of cinematic conventions (especially montage). Thus, because 'realist' films make sense within the patriarchal conventions of justice and logic, they fail to destabilise these conventions on both an extra- and intra-diegetic level. The ideological significance of classical realism, when examined specifically from the perspective of sound and the gendered voice and body, is discussed in greater detail below.

\footnotetext{
${ }^{2}$ In a similar project, radical feminist writers such as Annie Leclerc and Lucy Irigary have questioned the very structure of language and its implicit positing of subjectivity as male.
} 


\section{Eisenstein and the "Woman Question"}

What then, given the shortcomings of classical 'realism', do Eisenstein's films have to say to women in general and feminist filmmaking in particular? As I have mentioned above, Soviet cinema is not generally associated with feminist concerns: indeed the most significant feminist analysis of Eisenstein's films highlights the predominantly negative/passive portrayal of women throughout his work. Judith Mayne's essay 'Soviet Film Montage and the Woman Question' begins with a brief discussion of one of Kuleshov's experiments in the practice of photo-montage, namely the construction of a female figure from "the lips of one woman, the legs of another, the back of a third, and the eyes of a fourth", a project which she suggests was born of the fantasy of creating an idealised, non-threatening female form (Mayne, 1989: 29). Mayne also identifies a problematic gender dynamic in Eisenstein's films, whereby she claims that women are associated through montage with the concrete, while men remain abstract. She argues that rather than offering a dialectical reading, this approach reinforces the type of binary oppositions which have dogged feminism for so many years. In this essay, she says:

Potemkin is marked by the impossible reconciliation of the abstract and the concrete, qualities that the film has defined as male and female, respectively. Indeed, the female body in Potemkin comes to represent the flesh in an absolute sense, that is, flesh as an excess, a superfluousness, which resists the process of abstraction (Mayne, 1989: 34).

Mayne argues that Eisenstein uses female figures to connote the realm of the body, whereas his treatment of men/masculinity tends more toward the metaphorical. She cites the example of the pince-nez in The Battleship Potemkin: when we see it for the first time, it stands alone to signify the physician, whereas the second time it is identified with a woman's face. Mayne claims that through this gender dynamic, femaleness comes to signify that which exists beyond culture, while maleness is associated with the abstract, the mental aspect of physicality and culture. Similarly, she argues that the juxtaposition between the political and emotional responses of the men and women sets up a sexual dichotomy which undermines the power of the masses. Mayne is quick to point out that she is not critiquing sex-role stereotyping (since Eisenstein was bound to be influenced by the gender politics of the day) but is concerned instead with the sexual tension that is at the base of the opposition between 
the concrete and the abstract and that is central to the textual workings of Eisenstein's films. Speaking of October, she says:

It is perhaps tempting to argue that this troublesome representation of female agency has more to do with Sergei Eisenstein's particular disposition towards women than with the sexual politics of film narrative in the Soviet Union. I would argue, rather, that Eisenstein's visions of the sexual contours of revolution offer a representation "in amazingly bold relief"...of a dynamic that emerges in many Soviet films of the period (Mayne, 1989: 42).

In other words, Mayne identifies within the actual technique of montage a use of binary oppositions that is necessarily linked to gender dimorphism. I would argue, however, that if a biologically determinist account of human nature appears to pervade Eisenstein's films, it has less to do with montage itself than with gender relations at the time. Although Eisenstein applied the principles of the Yin and Yang with mathematical precision (referring to the Chinese numeric system, which rather than having any sense of quantity is concerned almost exclusively with the male and female categories of odd and even), he did so in the context of the dialectic (two opposite principles through whose interaction the world is built, maintained and moves). Speaking of this application of odd and even to his montage techniques, he said: '...it is not so much a matter of the alternation of odd and even as the feeling of an apparent mutual penetration of two complexes belonging to two opposite principles of phenomena' (Eisenstein, 1987: 242-3).

Though this notion of gender dichotomy is indeed questionable vis à vis the goals of feminism today, it is important to remember that gender issues were subsumed by the greater class struggle of Socialism at that time. Eisenstein used what he perceived as 'organic' opposites around him to structure his films (nature and culture, darkness and light) and evidently extended this notion of binary opposites into the category of gender. Like many of his Socialist contemporaries, his interest in and subsequently his understanding of gender as a thematic concern was overshadowed by the primary (class) struggle, and this clearly carried into his films. But, unlike classical narrative film, whose identification with a male hero inevitably involves the sexual objectification of women (the male gaze), the subjugation of women is not necessarily an inherent aspect of montage cinema, a point which I think is well illustrated by its successful appropriation for the purposes of political feminist cinema. Instead, I would argue that the gender dynamics which we observe in Soviet filmmaking in the 
1920s and 1930s are reflective of the greater conflict between socialism and feminism. As Heidi Hartmann has said of Marxism, though I think the quote can be extended to refer to socialism in general, at least in the past: 'The marriage of Marxism and feminism has been like the marriage of husband and wife depicted in English common law; Marxism and feminism are one, and that one is Marxism' (Hartmann, 1981: 2).

Although, as Mayne suggests, the male-female dichotomy in films such as The Battleship Potemkin and October, stands out from the supposed 'unity' of the rest, this is not indicative of an inherent tendency in montage cinema to polarise male and female. Although female figures undoubtedly function ambiguously in the films, certain sequences could also be said to foreground important issues concerning socialism and gender relations. For example, in October, the juxtaposition of the women soldiers with the statues symbolizing woman as child-bearer could be read as begging important questions regarding the role of women in private and public life at that time, questions which are indeed still relevant in contemporary western society. As Andrew Britton notes, the female soldiers are monstrous because they are like women and they are monstrous because they are not like women (cited in Mayne, 1987, 41). Though this is far from a 'positive' representation, it opens up important questions regarding gender and encourages dialectical reading in a way which realist cinema often fails to do.

Ultimately, Mayne seems to be saying that form and content are inseparable. However, while the form (i.e. montage) has evolved out of the revolutionary politics of Socialism, this is not necessarily its only potential political application. For example, a radical film employing montage techniques such as Laura Mulvey's Riddles of the Sphinx could be said to engage dialectically with gender politics but neglect or even negate class dynamics (from a Socialist viewpoint). What is of interest to this discussion is the fact that so many avant-garde filmmakers have successfully appropriated montage, as we know it from Eisenstein's earlier work, for the purpose of radical feminist politics. Thus, irrespective of the gender oppositions noted by Judith Mayne, montage as an art form and a political strategy is still about radical realignments of power or, to use Mayne's own words, the 'quintessential technique of an art form devoted to dynamic movement and dialectical tension' (Mayne, 1989: 27). 


\section{Visual Montage and Feminist Cinema}

Although, much early feminist work was informed by the principles of cinema verité (Mulvey, 1979: 3-10), there is a significant body of work which can be said to be inspired by Eisensteinian principles of montage and artifice. Examples are found not only in the avant-garde tradition of the 1970s (Jan Oxenburg, Barbara Hammer, Yvonne Rainer, Sally Potter and Laura Mulvey), but also among contemporary artists such as Tracey Moffat and Rose Troche. Cuban filmmaker Sara Gomez uses a kind of macro-montage in One Way or Another (1974) by intercutting narrative and documentary formats, a device which also underpins Michelle Citron's Daughter-Rite (1978), Stephen Burke's After '68 (1993) and Su Friedrich's Hide and Seek. According to Kaplan, this technique makes us aware of the constructed nature of both realism and documentary, prevents emotional immersion in the plot and encourages a critical awareness of the functioning and limitations of both formats: "The shift in modes makes us aware of our 'addiction' to narrative; it makes us think about that addiction, and about our resistance to the more difficult, cognitive mode' (Kaplan, 1988: 194). One Way or Another has much in common with Eisenstein's The General Line, not only because they both use montage to political effect and share the theme of revolutionary change but also because they are both deeply concerned with the fusion of the political and the personal and with the need to convince audiences of the link between the concrete (old slums being demolished to build new housing projects, old farming methods being replaced by new machinery) and the abstract (the happiness of individuals). Eisenstein consistently stated that form should mirror content. In both of these films, it is through a powerful and complex juxtaposition of images that they succeed in achieving this goal.

Also of interest in this respect is Trinh T. Minh-ha's re-appropriation of the ethnographic documentary tradition. According to Scott MacDonald (MacDonald, 1993: 150), the dense montage of Reassemblage is reminiscent of the Soviet use of montage within the political polemics of the 1920s. Trinh T. Minh-ha's rejection of linear narrative format also returns us to Eisenstein's discussion of basket-weaving, which he uses to describe the complex interweaving of narrative and formal structure. In A Question of Silence, Marleen Gorris combines a symmetrical narrative structure with strategies such as vertical montage, intellectual montage and subversive laughter to create a distancing effect. The conscious mixing together of genres and styles, combined with the circularity or interlocking of narratives as well as the use of 
repetition are all techniques which Eisenstein employed in his quest for an antinaturalist, anti-linear cinematic form. This is a cinema which, according to Laura Mulvey, aims 'to free the look of the camera into its materiality in time and space, and the look of the audience into dialectics, passionate detachment' (Mulvey, 1975: 18).

In a manner similar to the Soviet filmmakers and photomontage artists of yesteryear, these filmmakers operated on the basis that realism as a style could not change consciousness because it did not depart from the forms that embody the old consciousness. They argued that it was only in the self-consciously subjective production of meaning that women artists and filmmakers could successfully reject the patriarchal language of conventional cinema and carve out new - unapologetically feminist - spaces in which to tell their stories. However, despite the fact that some filmmakers continue using these techniques for political effect, it is arguable that film and photo-montage are no longer ostensibly a part of a modernist or postmodernist art movement. In the current culture of hip - yet for the most part politically vacuous textual borrowing, the sheer ubiquity of these forms has neutralised their political impact, and it is likely that original sources frequently go unrecognised. It is in this context of a visually saturated culture that a reappraisal of the sound-image relationship in film as a possible strategy for producing new meanings could be useful.

\section{Eisenstein and Sound}

Many critics have lamented the subordination of sound to image. The manifesto of Eisenstein, Pudovkin, and Alexandrov attacked just this point, calling for sound that was not merely redundant, whether it was synchronous or not (Doane: 1985: 565).

Although Eisenstein did not work with synchronous sound for much of his filmmaking career, he wrote extensively on this theme and seemed extremely concerned with the project of integrating an acoustic element into his films (Eisenstein, 1987: 216-297). The 1928 joint Manifesto with Pudovkin and Alexandrov recommended a strong explosion, divergence, and counterpoint opposition of the elements of sound and the elements of representation, or a 'hammer and tongs approach' that would open up 'new possibilities for the development and perfection of montage' (Taylor, 1998: 80-81). Eisenstein said that sound in film must not be reduced to the mere recording of dialogue - he emphasised the collision of disparate 
and conflicting elements in montage in order to produce, in the synthesis, new concepts. Accents within each shot came from the various visual and audial lines and, according to Eisenstein, these accents were most effective when the visual accent counterpointed the musical accent.

Therefore his use of filmic music, unlike that in classic film, did not merely complement the image track as an add-on dimension, but was rather interwoven into a complex whole. He used music like ideograms in Japanese writing, whereby separate signs, originally representational, were superimposed to create new signs whose meaning was the result of a metaphorical operation. Elements distinct in their oppositions to one another were integrated into a continuous whole along a linear chain or polyphonic stream. For The Battleship Potemkin, Eisenstein asked Edmund Meisel to reject the usual melodic quality and emphasis on bare rhythmic percussion beat, especially for the 'music of the machines' in the encounter with the squadron, in favour of a counterpointing between music and images, which would arouse pathos (ex-stasis, ecstacy) in the viewer.

According to David Bordwell, the break between the two distinct epistemological phases in Eisenstein's work (Bordwell, 1974/5) comes somewhere between the last silent and the first sound films. It is therefore possible that the use of sound is what brought Eisenstein away from the 'exposed nerve of montage' and closer to a more emotional cinema. In Nonindifferent Nature he says:

In our Manifesto of 1928, we proclaimed the stark separation and opposition of sound and image as a way of anticipating a future counterpoint... In my opinion, what characterizes the new phase of audio-visual montage is its allegiance to the increasing homogeneity of the polyphonic harmony of montage...

Formally, the counterpoint of montage seems to recreate that delightful moment of becoming, of consciousness, when the two preceding moments have been overcome, and the world, fragmented by analysis, falls back again into a whole, breathes life back into all the reciprocal relations between isolated particulars, and presents to a stunned consciousness the perceived fullness of a synthesized world (Eisenstein, 1987: 165-166, 171).

However, montage does not necessarily lose its potential for conflict or shock through this more complex and sophisticated process of synthesis. ${ }^{3}$ In fact, this approach may be of more value to contemporary feminist film than a cinema based solely on the

\footnotetext{
${ }^{3}$ See Jacques Aumont's Montage Eisenstein (1987) for a thorough discussion of this topic.
} 
principles of deconstruction, fragmentation and alienation. The following is an attempt to problematise sound-image synchronization in classical cinema from the point of view of gender, and to argue - using a number of contemporary films - that Eisenstein's concept of sound-image synthesis, underpinned as it is by a dialectical tension between politics and pleasure, offers radically different possibilities for feminist filmmaking. First, however, it is necessary to examine the gendered nature of the voice-body relationship in film and the concept of the 'acoustic gaze'. 


\section{Sound, Suture and the Female Voice in Cinema}

In spite of the supposed primacy of the image over sound in cinema, many theorists argue that it is in fact the psychological functioning of sound that sutures the viewer/listener into the fantasy of reality. According to Kaja Silverman (Silverman, 1988), acoustic realism is predicated upon a striking paradox, whereby a film's soundtrack is more capable of engaging the audience emotionally if all traces of static or background noise have been eliminated. This 'pure', manipulated soundtrack with unrealistic dialogue satisfies the illusion of reality, thus sewing the viewer into the narrative. On the other hand, realistic recordings featuring background noise in which sentences are jumbled, unfinished and punctuated by non-phonemic sounds produce an alienating effect or Verfremdungseffekt. Thus, in much the same way that classical film uses visual codes to draw the viewer into an illusion of reality, Hollywood's emphasis on diegetic speech acts (synchronisation, post-dubbing, voice-off and voiceover) helps to suture the viewer/listener into what Stephen Heath describes as the 'safe place' of the story, thus concealing the site of cinematic production (Heath, 1981: 55).

Silverman further argues that embodiment and disembodiment of the voice in cinema are complicated by the fact that diegetic speech acts (synchronisation, post-dubbing, voice-off and voice-over) are sexually differentiated in much the same way as the gaze (Mulvey, 1975). Often, the male voice is located at the point of apparent textual origin, for example through the use of male voice-over, while the female voice is contained within the story. Silverman argues that in classical Hollywood cinema, women speak only synchronously, their stories unfolding through male narrative voice-overs. The physical identity of a female narrator must always be disclosed because the woman's voice and body have to be unified in order to satisfy the desire of the male gaze and synchronisation marks the point of 'embodiment' (according to Silverman, the only exception in Hollywood film is that in Letter to Three Wives). Michel Chion actually compares the localisation of a previously unlocalised voice to the performance of a striptease, whereby the moment of 'deshabille' (the point of physical revelation, at which it is no longer possible to deny the absence of the penis) is likened to the discovery of the mouth from which the voice issues (Chion, 1982: 32-33). Thus the female body becomes the site of both anatomical and discursive lack and Silverman concludes that to embody a voice is to feminise it. So, while the female subject is associated with spectacle, castration (anatomical lack) and synchronisation 
(discursive lack), the male subject is aligned with the gaze, the phallus (anatomical power) and that which exceeds synchronisation (discursive power).

Silverman points out that there are only established deviations from synchronised sound. In the case of post-dubbing, male voices always come from male bodies and female voices always come from female bodies. Similarly, the voice-off device is effectively an extension of the rule of synchronisation: although it emanates from beyond limits of the frame (its source is not visible at the moment of emission), it does not exceed the limits of the diegesis, and it is always re-embodied. The voiceover, on the other hand, is coded differently in terms of its relation to main diegesis. The disembodied voice-over (a 'voice-on-high' which preserves its integrity) is almost exclusively male in the Hollywood film, whereas female voice-overs, particularly in film noir, are almost always linked up with the female body and are usually subverted from their initial position of power. According to Silverman:

There is a general theoretical consensus that the theological status of the disembodied voice-over is the effect of maintaining its source in a place apart from the camera, inaccessible to the gaze of either the cinematic apparatus or the viewing subject - of violating the rule of synchronisation so absolutely that the voice is left without an identifiable locus. In other words, the voice-over is privileged to the degree that it transcends the body (Silverman, 1988: 49).

Mary Ann Doane states that:

When the voice-over is introduced in the beginning of a film as the possession of the female protagonist who purportedly controls the narration of her own past, it is rarely sustained... Instead, voices-over are more frequently detached from the female protagonist and mobilised as moments of aggression or attack exercised against her (Doane, 1987: 150).

This is the case even in films such as The Color Purple and The Piano, which, in spite of giving their female protagonists a 'voice' in the form of first-person narration, confine their voices to inner monologue and employ self-concealing editing techniques to constantly suture the female voices back into the interior of the story. 


\section{Disembodying the Female Voice}

Given that embodied speech is the predominant way in which women are diegetically interiorised and constituted as anatomically and discursively lacking, the aim of 'disembodying' the female voice is to subvert the conventional sound/image relationship and thus restore the female voice as potent, authoritative and removed from the passive, voiceless and sexual function which it is assigned in classical cinema. Although there is a vast body of avant-garde work which disrupts conventional sound-image relationships, very few directors have sought to interrogate this relationship from a specifically gendered perspective. Those that do, for example Patricia Gruben in Sifted Evidence (1980), Laura Mulvey and Peter Wollen in Riddles of the Sphinx (1977) and Jan Oxenburg in Home Movie (1975), have been restricted almost exclusively to the festival circuit and are generally unavailable on video. Meanwhile, there is also a significant body of installation and video work that uses sound to radical effect. However, much of this work is still predominantly deconstructionist in its goals and rarely reaches mainstream audiences. What is of interest in this context, therefore, is the 'sounding out' and analysis of a body of filmic work that could be described, by virtue of its employment of acoustic montage, as belonging to a non-alienating cinema of resistance and pleasure. In recent years, a number of key films have emerged which are unquestionably political, in that they accommodate a clearly feminist subjectivity, but which do not resort to realism, instead foregrounding - predominantly acoustic - artifice to interrogate the medium itself. These include Michael Verhoeven's The Nasty Girl (1989), Stephen Burke's After '68 (1993), Tracey Moffat's Nice Coloured Girls (1987), Rose Troche's Go Fish (1994) and, to a lesser extent, Lars von Trier's Dancer in the Dark (2000). I will attempt to demonstrate how - through radical sound-image juxtaposition - these films achieve what Kaplan referred to as a 'positive cinema of reconstruction' (Kaplan, 1988: 140-141).

\section{Speaking Women's Histories}

Although not immediately apparent, The Nasty Girl, After '68 and Nice Coloured Girls have much in common. Firstly, their use of innovative soundtracks works to reinstate the authority of the female voice, and to challenge official (patriarchal) accounts of history. Secondly, they all operate in an aesthetic framework that although non-realist - could still be described as popular. Both After '68 and The Nasty Girl are notable, not only because their directors are male but also for the 
degree to which these directors relinquish authorship to the Frieda and Sonja characters respectively. In the case of After '68, Frieda controls her own narrative through extra-diegetic voiceover. The woman we hear is the adult the younger woman will become but we never actually see the adult, nor have we any indication of the time lapse between the actual events and their telling. It has been suggested by Sarah Kozloff that a temporal disjunction between the off-screen self of the narrator and the figure we see is a sign of trauma (Kozloff, 1988: 53-62). Likewise, Kaja Silverman contends that when "the voice-over is autobiographical and self-revealing", it frequently "takes the form of temporal regression, a movement back to a prior moment in the speaker's life which accounts for his present condition" (Silverman, 1988: 52-53). It could therefore be argued that the narrative of After ' 68 actually relates the trauma that has divorced the voice from the image. In defiance of cinematic conventions, this crisis is never resolved because Frieda's extra-diegetic voice is never reconciled with her intra-diegetic body. This device is rarely - if ever seen in Hollywood films, whose stories told in flashback are always traced back to a narrator who is firmly rooted in the 'present ' of the diegesis, e.g. The Color Purple. Although the intra-diegetic events are not devoid of a soundtrack, the voices of Frieda and her mother are not heard within the diegesis. ${ }^{4}$ Instead, Frieda's narrative voiceover remains at the outer limits of the diegesis, from which point she has the power to speak over her own story, over inserts of documentary footage and over history in general.

Both music and narrative voiceover are frequently counterpointed with the film's images to ironic effect. The rock ' $n$ roll score, rather than complimenting or corroborating the images of violence and oppression (as might, for example, soulful Republican ballads), sets them against the wider context of global popular culture. This appears to be in keeping with many of Eisenstein's theories on audiovisual montage in that it opens up the potential for a dialectical reading, yet is neither radically disruptive nor lacking in emotional appeal. The final sequences, in particular, in which Frieda and her mother leave Derry in a taxi, are highly emotive. Yet the romantic music and stunningly lit cinematography stand out in stark contrast to the Derry street scenes through which they pass (soldiers warming themselves by fires lit in petrol drums, Frieda's ex-boyfriend in a balaclava), rendering the concept of closure - both of the film and the Troubles - problematic. The voice-over narration at

\footnotetext{
${ }^{4}$ The only exception to this rule is the scene in which Frieda's mother introduces Mrs. Craig.
} 
the beginning of the film is also juxtaposed with dissonant images: while the narrator speaks of international political events which occurred in 1968, such as the student protests in Paris, the Vietnam War, rioting in Czechoslovakia and the assassination of Martin Luther King, we see nuns smoking and schoolgirls in a convent. The political is thus rendered personal (and vice versa) and it is through this kind of sound-image juxtaposition that film continues to negotiate the tensions between fiction and reality and between male authority and female subjectivity.

As in One Way or Another and Julian Schnabel's Before Night Falls (2000), After '68 is interspersed with black-and-white newsreel and documentary footage of the troubles. It is highly significant that, rather than preserving the original voice-overs, it is Frieda who continues to talk over these images, substituting the (traditionally) male, disembodied voice with her own. As discussed earlier in relation to One Way or Another, this macro-montage of fiction and documentary also serves as a powerful reminder of the inadequacy of each format to present faithful accounts of history yet, through the juxtaposition of the two, builds a new synthesis of meaning. The official media version of events, audible within the diegesis on the radio and television, is also undermined by the narrator's voice, a feature which is also seen in Pat Murphy's Maeve (1981), whose eponymous protagonist speaks over an Ian Paisley speech on television. However, rather than encouraging personal identification with the protagonist, these films maintain a critical distance through the dislocation between voice-over and intra-diegetic body, thus asserting the story as personal on one level, yet universal/political on another. In After ' 68 , this universality of the events portrayed is also related through the anonymity of the narrator, whose name is revealed only once before the closing credits. In a similar vein to Eisenstein's later work, Burke does not engage directly with the principles of a deconstructionist cinema (alienation), nor does he resort to the classical fiction's 'fully sensory reality' (identification). Rather, somewhere between the two, he achieves a level of synthesis which emotionally engages the viewer yet encourages critical distance. The overall effect of this complex sound-image juxtaposition is that the audience can be partially immersed in a story but at the same time encouraged to make their own sense of political events in Northern Ireland. 


\section{Retelling Tales of Old: The Nasty Girl}

Like After '68, Michael Verhoeven's The Nasty Girl (1989) is also about a woman's attempts to reclaim history, in this case drawing on the true story of Anja Rosmus in Passau. Although a lot less realist in visual terms than After '68, the film uses similar voiceover devices to ensure Sonja's authorial control. At several points throughout the film, she also appears to control the actual media with which her story is told, using a microphone and speaking directly to camera as if making and starring in a documentary about her past. Rather than divorcing the narrative voiceover from the intra-diegetic character, however, Verhoeven confuses the two. Sonja frequently detaches herself from scenes, speaking directly to the camera, but this is a non-realist use of embodied voiceover, unlike the flashback techniques normally used to reembody the narrator's voice, which serves to give the narrator ownership of the story.

Verhoeven uses audiovisual and intellectual montage to set up the contradictions at the heart of the film, namely the disparity between official accounts of history and subjective memory. Thus interviews with male representatives of institutions such as academia and the Church, which are underpinned by official rhetoric, contrast sharply with the personal, subjective accounts given by Sonja's grandmother (an acknowledgement of the power and importance of oral memory). In the key opening scenes, which rely on a complex sequence of audio-visual montage, the drunken male voices of Nazis in a bar contrast sharply with the articulacy of the female narrator. Indeed it is significant that the only point at which the Neo-Nazis are given a voice in the film is the scene in which a group of new recruits appropriates the mindless, institutionalised rhetoric of prayer before a military routine. It is unclear as to whether Sonja's opening seminar, in which she appears in front of a slide projection of the Bundeskanzler ("It all began when...") is located at the inside or outside of the diegesis, as is the case when Sonja as narrator addresses the camera directly to introduce her town, her family home and the Zumtobel chocolate factory. In this opening sequence, a male voice (off-screen), presumably a member of the audience, tells her that the projected image is too far right, then too high - possibly suggesting male control of the image - but she ignores him and continues with her talk. This is followed by a shot of graffiti on a church wall 'Where were you between 1939 and 1945? Where are you now?', which is being erased by two Gastarbeiter or immigrant workers, which might be read as symbolising man's ability to erase history, the ease 
with which the written word can be manipulated and the importance of oral memory in overcoming this.

Throughout the film, the voice-image relationship is constantly used to challenge the notion that past and present can be separated in contemporary Germany. The threatening voices of the townsfolk recorded on Sonja and Martin's answering machine are matched with an image of two young men arm wrestling, presumably Neo-Nazis. Likewise, Sonja's conversation with her mother about the townsfolk who were involved in Nazi activities in the past is set against the image of young men drinking in a Bierkeller, an image which recurs throughout the film. When Sonja provokes the outrage of the entire community, the scene in which her family listens to threatening phonecalls on the answering machine is superimposed against moving images of the town, suggesting their final detachment from the society in which they live. Verhoeven's use of overtonal montage is also significant in the film (black and white mixed with colour). Eisenstein noted of his use of overtonal montage in Ivan the Terrible (Part II), that the structural system enabled a leap from the sphere of the representational to that of its opposite in the nonrepresentational" (Eisenstein, 1987: 310-326). Similarly, The Nasty Girl consistently evades realism by using static photo backgrounds instead of realistic sets, particularly to represent institutions such as the state, the church and the law, implying their constructedness and artificiality. In the court scene, the surrealist backdrop featuring the female figure of Justice waking from her slumber when the verdict in announced in Sonja's favour is a powerful piece of what could be called micro-montage (montage within the shot). Not only do these devices interrogate the institutions of law and order within the diegesis but they also remind us of the artifice necessarily involved in any attempt at representing reality.

The issue of women's need to reclaim history through the oral tradition, as addressed by Trin T. Minh-ha in her writings on women and postcoloniality, ${ }^{5}$ is also a central concern of Tracey Moffat's short film Nice Coloured Girls. Although Silverman's hypothesis that diegetic exteriority is equated with discursive authority generally holds true, the disembodied voiceover is not always powerful if, for example, it is used ironically. In Moffat's film, disembodied male voiceover is used in a radically different way than, for example, in Amélie. Although a short film that is unlikely to

\footnotetext{
${ }^{5}$ See Trin T. Minh-ha. Woman, Native, Other: Writing Postcoloniality and Feminism. Bloomington: Indiana University Press, 1989.
} 
have reached a large audience, Nice Coloured Girls is a useful example of how disruptive sound-image techniques can create potent messages, not only relating to the diegesis of the film but also about the politics of historical and media representation. By using layers of image, voiceover and subtitles, Moffat arguably says more about gender and the aboriginal woman's complex relationship to colonialism in 30 minutes than could be achieved by a classic feature-length treatment of the subject. By overlaying the image track with a male voiceover (the voice-over of colonist, Lieutenant William Bradley, reading from his diary entries) and 'speaking' the subjectivity of the Aboriginal women through subtitles, Moffat delivers a powerful commentary on the way in which Aboriginal reality has traditionally been spoken from a white perspective as well as spoken to a white perspective. The male voice over, which is an historical account of white men's first encounters with Aboriginal women, at first appears incongruous with the images of contemporary Aboriginal women, yet develops to deliver an insightful explanation of their present relationship with white men and the ways in which they have come to internalise a western, male concept of their own sexuality, at the same time using this to exploit white men. In addition to the voice-over device, the juxtaposition between past and present is also achieved through sounds of rowing boats, bird song and Aboriginal language. According to Lisa French, "The sounds of the urban and rural landscape are heard simultaneously and the dislocation between sound and image is one of the elements which make Nice Coloured Girls an innovative film. An example of such dislocation is the film's ending (which also echoes the beginning): the image is a shot of the cityscape while the audio consists of a soundscape of the rural environment and the colonists voice-over."(French: 2000). Thus the sound-image relationship constructs a highly complex discourse about past and present, about coloniser and colonised, about ownership of history and the media and about the grammar of cinema itself. Despite the formal complexity of the film, however, it is nonetheless engaging from the point of view of narrative, and is extremely rich in visual imagery.

\section{Speaking Out of the Closet}

Although the widely acclaimed lesbian romantic comedy Go Fish, written by Rose Troche and Guinevere Turner, is less obviously political than the films discussed above, it nonetheless succeeds in subverting the conventional sound/image relationship on various levels. In an article in Film Ireland, Suzy Coen refers only in passing to the acoustic aspect of the film - "the sound recording is basic" (Coen, 1994: 
13) - concentrating instead on its visual and narrative qualities. However, closer examination reveals that Troche's experimental use of synchronised voice, voice-off and voice-over act as powerful mechanisms to push the film's relatively simple narrative (a lesbian love story) well beyond the boundaries of realism. In Go Fish, the characters' voices are frequently disjointed from their bodies, and matching of voices to lips is often avoided. In purely visual terms, realistic scenes are frequently intercut with surrealist imagery - milk being poured into coffee, a spinning top, hands joining together, words painted on a body, feet walking, pages of a book being turned, a young boy playing, and close-ups of lips, ears and hands. Although lesbian love and agricultural modernization have little in common, this technique is evocative of Eisenstein's The General Line, in which pathos is created by the transformation of everyday objects into an evocation of that epic lyricism sought by the Soviet director.

Significantly, the mechanism by which the viewer/listener oscillates between involvement in the narrative and alienation from it is controlled largely by the voice and by a disruptive sound-image relationship. As in The Nasty Girl and After '68, Max's voice speaks both inside and outside the diegesis, affording her a similar degree of authorial control over her story. However, other women's voices (e.g. Kia and Ely) are frequently used in surreal scenes, whereby the relationship between sound and image, or voice and body, is deliberately distorted. In Evy's case, this device is used to explore her relationship with her mother: an affectionate conversation in Spanish between mother and child is juxtaposed with a scene in which Evy leaves home after her mother discovers she is lesbian. Although it is Ely's and Max's story, and is told predominantly from Max's point of view as diary writer, the film accommodates multiple perspectives by relating the subjective experiences of several different characters through complex use of voice and music (e.g. after Ely first sleeps with Max, she hears music on her way home, and imagines a flower-seller congratulating her). At the end of the film, Turner's/Max's voice acknowledges the position of the cinematic apparatus by speaking directly to the viewer/listener. The realist illusion is again broken down and, as is the case with most of the political messages throughout the film, it becomes unclear whether this voice is delivered from inside or outside the diegesis.

More recently, Lars von Trier has challenged conventional sound-image techniques in Dancer in the Dark, which has been aptly described by many critics as an 'anti- 
musical'. Here, von Trier teases out complex emotional and political issues by using the full potential of cinema's audio-visual syntax, as opposed to relying solely on intra-diegetic devices such as character, dialogue or plot. Although not an overtly feminist film, it is told from the perspective of its female protagonist, a disenfranchised Polish factory worker in 1950s America. The film is both critique and celebration of the American musical and, at a deeper level, of the ideology which underpins the American Dream. However, rather than expressing this critique purely through characters, dialogue or narrative (all of which can also be accommodated by literature, for example) von Trier uses sound and vision to their full potential, producing a film in which form and content are inextricably linked. The choreographed dance scenes both complement and jar with the score, so that everything in the film is slightly off-key. Meanwhile, within the narrative itself, Selma's deteriorating eyesight increases her dependence on sound and song, which manifests itself in an increasingly off-kilter and claustrophobic soundtrack. Von Trier clearly breaks with the tenets of Dogme 95, using both visual and acoustic montage to create a highly stylised - yet also deeply engaging - film. In this synthesis, he thus constructs a dialectical discourse on the American Dream, ${ }^{6}$ both at the level of narrative content and stylistic form. In this sense, von Trier achieves the kind of political - and at the same time emotive - filmmaking advocated by Eisenstein, in which formal devices remind the audience that they are watching a film (in this case a film about the power of film) but at the same time do not deny emotional involvement. Like most of the films discussed here, Dancer in the Dark fully utilises the acoustic syntax of cinema to expose multiple and often contradictory perspectives, thus acknowledging a dialectical position, rather than attempting to simplify or interpret reality for the viewer in a way that fails to acknowledge the politics of representation.

However, experimental and art film excluded, examples of this type of approach to sound are relatively rare. Some recent - predominantly realist - films have integrated elements of innovation, for example Moufida Tlatli's The Silences of the Palace (1994), a film which deals, thematically, about the silencing of women's voices. Tlati contrasts music with heavy silence but the music and the silences take place mostly within the diegesis (i.e. the characters are actually singing or being silent). In a key

\footnotetext{
${ }^{6}$ Although it can be argued that most Hollywood films so this, the purpose is usually to create narrative conflict which is ultimately resolved in a closure whose ideological readings are relatively limited.
} 
scene, however, after Alia has witnessed her uncle prince raping her mother, the soundtrack goes entirely silent so that Alia's scream cannot be heard ${ }^{7}$. The same device is used at the end of Neil La Bute's In the Company of Men, although in this case it is the male's voice which is silenced and disempowered. The sequence, which shows Christine finally confronting Howard, is shot from her point of view, thus reinstating her subjectivity and serving as a clear indication of the director's sympathies. Although both films are predominantly realist in terms of their use of sound, these jarringly formal devices are highly effective, and one cannot help but wonder whether such films, with themes relating so specifically to the female voice, ${ }^{8}$ might not have been enhanced by more frequent use of such devices.

\section{Conclusion}

It is to be regretted that many feminist filmmakers, amongst them Pat Murphy, Rose Troche and, to a lesser extent, Sally Potter, have abandoned avant-garde techniques in favour of mainstream realism. Although this trend is presumably attributable to concerns of commercial viability, it poses a substantial threat to the praxis of a contemporary feminist cinema. Admittedly, there are considerable problems associated with the notion of a unified feminist cinema in a postmodern, postfeminist climate since designating bodies of work as 'feminist' tends to position the art as Other. However, as long as gender inequality persists in (post)modern culture and as long as gender issues - no matter how thematically radical and shocking - are subsumed within (and largely neutralised by) realist narratives, the need for a lively, self-questioning feminist cinema will continue.

Secondly, in a culture that is becoming increasingly image-oriented, the power of visual montage has been both undermined and depoliticised. Given the power of the voice and the pivotal role which it plays in its juxtaposition with the image, its interrogation and reappraisal could therefore provide useful strategies for a new feminist cinema. The significance of this project is perhaps best underlined by the inevitability that future sound technology will persist in its quest for realism and three-dimensionality, thus perfecting the acoustic virtual reality of the cinematic

\footnotetext{
${ }^{7}$ See also Shoma A. Chatterji's comments on cinematic silence as a metaphor of the oppressed in 'The CultureSpecific Use of Sound in Indian Cinema', paper presented at the International Symposium on Sound in Cinema, London, April 15 - 18, 1999, pp. 14-19 (http:/www.filmsound.org/india, accessed 15.11.02).
} 
space. In this context, innovative use of sound, while by no means the sole alternative to classic cinematography, may provide a significant channel of resistance to the increasing formal homogeneity of feminist filmmaking. Eisenstein's espousal of a sound-image relationship that delivers, in the synthesis, both critical distance and pleasure provides a potential framework for new, more acoustically-oriented approaches to film-making. Such approaches not only deflect attention away from the gaze and from sexualisation and fetishisation of the female body, they also provide filmmakers with a more flexible medium with which to interrogate language, subjectivity and the cinematic apparatus itself, and audiences with the possibility of embracing such ideas without sacrificing pleasure.

Some of the films analysed in this chapter are also discussed in 'Noises Off: the Unsung Potential of Sound in Cinema', in Film and Film Culture (2). Waterford Institute of Technology, 2002.

\footnotetext{
${ }^{8}$ The Silences of the Palace deals with the oppression of women through the silencing of their voices, while In the Company of Men is the story of a deaf secretary's humiliation by two businessmen.
} 


\section{Filmography}

Accused, The (Jonathan Kaplan, 1988, USA/Canada)

After '68 (Stephen Burke, 1993, Ireland)

Age of Innocence, The (Martin Scorsese, 1993, USA)

Amélie (Jean-Pierre Jeunet, , 2001, France/Germany)

Battleship Potemkin, The (Sergei M. Eisenstein, 1925, Soviet Union)

Before Night Falls (Julian Schnabel, 2000, USA)

Chasing Amy (Kevin Smith, 1997, USA)

Color Purple, The (Steven Spielberg, 1985, USA)

Dancer in the Dark (Lars von Trier, 2000, Denmark)

Daughter-Rite (Michelle Citron, 1978, USA)

General Line, The (Sergei M. Eisenstein, 1929, Soviet Union)

Hide and Seek (Su Friedrich, 1996, USA)

Girl's Town (Jim McKay, 1996, USA)

Go Fish (Rose Troche, 1994, USA)

Home Movie (Jan Oxenburg, 1975, USA)

I've Heard the Mermaids Singing (Patricia Rozema, 1987, Canada)

In the Company of Men (Neil La Bute, 1995, USA)

Ivan the Terrible (Part II) (Sergei M. Eisenstein,1958, Soviet Union)

Letter to Three Wives, A (Joseph L. Manckiewicz, 1949, USA)

Maeve (Pat Murphy, 1991, GB)

Nasty Girl, The (Michael Verhoeven, 1989, Germany)

Nice Coloured Girls (Tracey Moffat, 1987, Australia)

Nora (Pat Murphy, 1999, Ireland/UK)

October (Sergei M. Eisenstein, 1927, Soviet Union)

One Way or Another (Sara Gomez, 1974, Cuba)

Piano, The (Jane Campion, 1993, Australia)

Question of Silence, A (Marleen Gorris, 1982, Netherlands)

Reassemblage (Trinh T. Minh-ha, 1982, USA)

Riddles of the Sphinx (Laura Mulvey/Peter Wollen, 1977, UK)

Sifted Evidence (Patricia Gruben, 1980, USA)

Silences of the Palace, The (Moufida Tlatli, 1994, France/Tunisia)

Strike (Sergei M. Eisenstein, 1925, Soviet Union)

Philadelphia (Jonathan Demme, 1993, USA)

Wag the Dog (Barry Levinson, 1997, USA) 


\section{Bibliography}

Aumont, J. Montage Eisenstein. Bloomington and Indianapolis: Indiana University Press, 1987.

Bakhtin, M. The Dialogic Imagination. Ed. M. Holquist. Trans. C. Emerson and M. Holquist. Austin: Austin University of Texas Press, 1981.

Bordwell, D. 'Eisenstein's Epistemological Shift'. Screen. Volume 15, Number 4, 1974/5: 22-46.

Bordwell, D. The Cinema of Eisenstein. Cambridge, Massachusetts and London: Harvard University Press, 1993.

Chion, M. La Voix au Cinéma. Paris: Éditions de L’Étoile, 1982.

Coen, S. 'Girl Crazy'. Film Ireland. October/November: 12-13, 1994.

Doane, M.A. 'The Voice in the Cinema: The Articulation of Body and Space'. Ed. B. Nichols. Movies and Methods: An Anthology, Vol II. Berkeley; Los Angeles; London: University of California Press: 565-576, 1985.

Doane, M.A. The Desire to Desire. The Woman's Film of the 1940s. Bloomington: Indiana University Press, 1987.

Eisenstein, S. Nonindifferent Nature, Film and the Structure of Things. Trans. H. Marshall. Cambridge: Cambridge University Press, 1987.

Foster, H. Ed. Postmodern Culture. London: Pluto Press, 1985.

French, F. 'An Analysis of Nice Coloured Girls'. Senses of Cinema, Issue No. 5, April 2000 (http://www.sensesofcinema.com/contents/00/5/nice.html).

Hartmann, H. 'The Unhappy Marriage of Marxism and Feminism: Towards a More Progressive Union'. Ed. L. Sargent. Women and Revolution: A Discussion of the Unhappy Marriage of Marxism and Feminism. Boston: South End Press: 1-41, 1981.

Heath, S. Questions of Cinema. London; New York: MacMillan Press, 1981.

Irigaray, L. This Sex Which Is Not One. Trans. Catherine Potter. Ithaca: Connell University Press, 1985.

Jameson, F. The Political Unconscious: Narrative as a Socially Symbolic Act. London: Methuen, 1981.

Johnston, Claire. 'Women's Cinema as Counter-Cinema'. Ed. B. Nichols. Movies and Methods: An Anthology, Vol I. Berkeley; Los Angeles; London: University of California Press, 1985.

Kaplan, E. A. Women \& Film: Both Sides of the Camera. New York and London: Routledge, 1988. 
Kozloff, S. Invisible Storytellers: Voice-Over Narration in American Fiction Film. Berkeley: University of California Press, 1988.

Leclerc, A. Parole de Femme. Paris: Éditions Grasset and Fasquelle, 1974.

MacDonald, S. Avant-Garde Film: Motion Studies. New York: Cambridge University Press, 1993.

Mayne, J. 'Soviet Film Montage and the Woman Question'. Camera Obscura, 19: 25$52,1989$.

McGarry, E. 'Documentary Realism and Women's Cinema'. Women and Film, Vol. 2, No. 7: 50-59, 1975.

Mulvey, L. 'Film, Feminism and the Avant-Garde'. Framework No. 10: 3-10, 1979.

Mulvey, L. 'Visual Pleasure and Narrative Cinema'. Screen, 16(3): 6-18, 1975.

Silverman, K. The Acoustic Mirror. The Female Voice in Psychoanalysis and Cinema. Bloomington and Indianapolis: Indiana University Press, 1988.

Taylor, R. The Eisenstein Reader. London: British Film Institute, 1998.

Wollen, P. Signs and Meaning in the Cinema. Bloomington: Indiana University Press, 1972. 